\title{
Influence of Selected Storage Temperatures on Wood Properties and its Biological Resistance After the Use of Methylxanthines
}

\author{
Klára Kobetičová, ${ }^{\mathrm{a}, *}$ Martin Böhm, ${ }^{\mathrm{a}}$ Jana Nábělková, ${ }^{\mathrm{b}}$ and Robert Černý ${ }^{\mathrm{a}}$ \\ Methylxanthine's fungicidal properties were investigated, with attention to \\ the temperature of treatment. Caffeine and theophylline treatments of \\ beech and spruce woods were applied for three months in the temperature \\ range of -20 to $40{ }^{\circ} \mathrm{C}$, simulating potential weather conditions in the \\ European region and temperatures specific for various wood applications \\ (cellars, wine cellars, room indoor temperatures, interior trusses). Effects \\ of the selected temperatures were considered without the influence of the \\ other possible factors, which have been considered in previous studies \\ (e.g. effects of temperature in combination with other factors such as UV \\ radiation, humidity, and chemical or biological degradation). Then, the \\ specimens were exposed to a mix of molds and fungi for three months \\ under controlled laboratory conditions in order to analyze a possible \\ subsequent biological attack. The results did not show any effect of \\ temperature of the methylxanthine treatment within the studied range on \\ the organismal activity. Caffeine exhibited a better protective potential than \\ theophylline and was more effective for spruce than for beech. The results \\ indicated the suitability of caffeine for protection of spruce and spruce- \\ based materials in interior applications at a stable temperature without \\ significant effects of UV and humidity.
}

Keywords: Wood treatment; Caffeine; Theophylline; Temperature; Biodegradation; Spruce; Beech

Contact information: a: Department of Materials Engineering and Chemistry, Faculty of Civil Engineering, Czech Technical University in Prague, Thákurova 7/2077, 16629 Prague 6, Czech Republic;

b: Department of Sanitary and Ecological Engineering, Faculty of Civil Engineering, Czech Technical University in Prague, Thákurova 7/2077, 16629 Prague 6, Czech Republic;

* Corresponding author: klara.kobeticova@fsv.cvut.cz

\section{INTRODUCTION}

Methylxanthines seem to be a prospective wood-preserving group of environmental-and health friendly substances (Broda 2020). They have a natural origin and are produced by some plants. The use of such natural herbal metabolites in wood preservation systems can reduce the usage of metal- or chlorine-containing pesticides. The most known methylxanthines are caffeine and theophylline. Caffeine is a substance that affects the central nervous system, and it is used in many applications - in food, drinks or drug and cosmetic industry. Theophylline is used as a drug in pills against asthma, and it has a relatively good toxicological potential for the use in practice (Kobetičová et al. 2020a). However, its application on wood has never been tested yet. In contrast, caffeine has been studied quite intensively in recent years (Ratajczak et al. 2018; Broda et al. 2018; Kwasniewska-Sip et al. 2018; Kwasniewska-Sip et al. 2019; Pánek et al. 2020; Šimůnková et al. 2021).

Kobetičová et al. (2021). "Caffeine \& wood protection," BioResources 16(3), 6231-6243. 6231 
Effects of the ordinary temperatures occurring in the European climate have not been tested in relation to the properties of treated wood, although their influence is decisive. The effect of application temperature on a possible subsequent biological attack has not been analyzed either. All mentioned studies were performed at the prescribed laboratory temperature $(20 \pm 2){ }^{\circ} \mathrm{C}$ or the temperatures required for the growth of organisms (20 to 35) ${ }^{\circ} \mathrm{C}$ or the performance of experiments was conducted according to standardized procedures or during successive cycles of accelerated aging in a climatic chamber (Ratajczak et al. 2018; Broda et al. 2018; Kwasniewska-Sip et al. 2018; Kwasniewska-Sip et al. 2019; Kobetičová et al. 2020; Pánek et al. 2020; Šimůnková et al. 2021).

Caffeine and theophylline treatments of beech and spruce were analyzed in a temperature range of -20 to $40{ }^{\circ} \mathrm{C}$. The treated wood samples were left in incubators for three months at selected constant temperatures $\left(-20,0,5,20\right.$, and $\left.40{ }^{\circ} \mathrm{C}\right)$ in the dark. The selected temperature was the only monitored parameter in this study, and its influence on the distribution and biocidal effect of studied substances was monitored. Penetration of the concentration of substances in the wood was also studied after methylxanthines treatments. The other set of wood samples was exposed to a mixture of fungi and molds for another three months and a possible subsequent biological attack was investigated afterwards.

\section{EXPERIMENTAL}

\section{Materials}

Chemicals

Caffeine $\left(\mathrm{C}_{8} \mathrm{H}_{10} \mathrm{~N}_{4} \mathrm{O}_{2}\right)$ and theophylline $\left(\mathrm{C}_{7} \mathrm{H}_{8} \mathrm{~N}_{4} \mathrm{O}_{2}\right)$ were purchased from SigmaAldrich, Ltd., Czech Republic. The substances were in powder form (> $98 \%$ purity). Deionized water was used as solvent for the preparation of aquatic solutions of caffeine (20 g.L. $\left.\mathrm{L}^{-1}\right)$ and theophylline (5.5 g.L $\left.\mathrm{L}^{-1}\right)$. The selected concentrations correspond to maximal permissible substances concentrations in water. The caffeine concentration 20 g.L $\mathrm{L}^{-1}$ was found to be effective against fungi on pine wood (Kwasniewska-Sip et al. 2018), and theophylline diluted in agar medium was $100 \%$ effective for fungi and molds from concentration 2 g.L.-1 (Kobetičová et al. 2019, 2020a). However, one can expect a lower bioavailability for pests on wood, therefore, the maximum permitted concentrations of the substances were employed in the present study. The solutions were sonicated for $24 \mathrm{~h}$. Then the solutions were cooled to room temperature and poured into containers to immerse the entire prepared wood samples. The molecular structures of the substances are described in Fig. 1.

a)

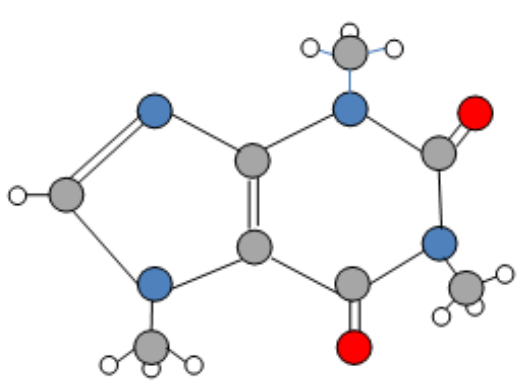

b)

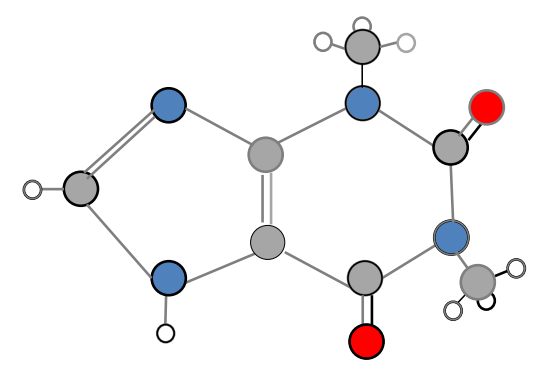

Fig. 1. Schematical structure of (a) caffeine and (b) theophylline, red points = oxygen, blue points $=$ nitrogen, grey points $=$ carbon, white points $=$ hydrogen 


\section{Wood materials}

All test specimens were prepared using spruce (Picea abies L.) and beech wood (Fagus sylvatica L.). They were purchased from a hardware store SEZAM, Ltd. Chrudim, Czech Republic. The samples showed no infection by molds and wood decay fungi. The specimens with a size of $(50 \pm 0.1) \times(20 \pm 0.1) \times(0.5 \pm 0.1) \mathrm{mm}$ (longitudinal $\times$ radial $\times$ tangential) were prepared. Tree samples of each substance and its control were used for biological tests, three samples for chemical analysis of substances concentrations and their controls in layers of woods, three samples for theophylline chemical analysis in lignin and cellulose experiments, and one sample + one control for the SEM analysis. Thus, a total of 112 wood samples were used (Table 1).

Table 1. Number of Beech or Spruce Samples Used for Caffeine and Theophylline Treatment and Their Controls for the Performed Analysis

\begin{tabular}{|c|c|c|c|c|}
\hline Analyze & \multicolumn{2}{|l|}{ Beech } & \multicolumn{2}{|l|}{ Spruce } \\
\hline \multicolumn{5}{|c|}{ Caffeine } \\
\hline & $\begin{array}{l}\text { No. of treated } \\
\text { samples + } \\
\text { control }\end{array}$ & $\begin{array}{l}\text { No. of control } \\
\text { samples } \\
\text { control }\end{array}$ & $\begin{array}{lr}\text { No. of } & \text { treated } \\
\text { samples } & + \\
\text { control } & \end{array}$ & $\begin{array}{lr}\text { No. of } & \text { control } \\
\text { samples } & + \\
\text { control } & \end{array}$ \\
\hline SEM & $1+1$ & $1+1$ & $1+1$ & $1+1$ \\
\hline $\begin{array}{l}\text { Chem. analyze } \\
\text { - wood layers }\end{array}$ & $3+3$ & $3+3$ & $3+3$ & $3+3$ \\
\hline Mass loss & $3+3$ & 3 & 3 & 3 \\
\hline \multicolumn{5}{|c|}{ Theophylline } \\
\hline SEM & $1+1$ & $1+1$ & $1+1$ & $1+1$ \\
\hline $\begin{array}{l}\text { Chem. analyze } \\
\text { - wood layers }\end{array}$ & $3+3$ & $3+3$ & $3+3$ & $3+3$ \\
\hline Mass loss & $3+3$ & 3 & 3 & 3 \\
\hline
\end{tabular}

Treatment of wood samples

Prior to the start of the experiment, all samples were dried at $105{ }^{\circ} \mathrm{C}$ for $24 \mathrm{~h}$ (this time period is sufficient to obtain a stable weight according to our previous experience), transferred to a desiccator, left to cool there on the laboratory temperature and then weighed $\left(m_{l}\right)$. The wood samples to be treated were then placed in an aqueous solution of caffeine $\left(20 \mathrm{~g} . \mathrm{L}^{-1}\right)$ or theophylline $\left(5.5 \mathrm{~g} \mathrm{~g} . \mathrm{L}^{-1}\right)$. The control samples were put in distilled water. Triplicates were prepared for each caffeine or theophylline solutions and for all controls (distilled water). The intake of the solution and the soaking time were adjusted and checked by continuous weighing of the samples (beech is significantly more permeable compared to spruce). The samples in substance solutions were stored in a thermostat in the dark and under a constant temperature $(20 \pm 2){ }^{\circ} \mathrm{C}$. All samples were then conditioned at $(20 \pm 2)^{\circ} \mathrm{C}$ to achieve a constant weight $\left(m_{2}\right)$.

\section{Microscopic analysis}

The microstructural morphology of the caffeine and theophylline was studied using a high-resolution Merlin-Zeiss electron microscope (FEG-SEM) with a secondary electron detector operated at an acceleration voltage of 5-15 kV, probe current of 200-600 pA and a working distance of 6 to $24 \mathrm{~mm}$. Vacuum-dried substances were glued to the aluminium stab using double-sided conductive carbon tape. Sputter coater Quorum SC7620 (Quorum Technologies Ltd.) was used to generate approximately $5 \mathrm{~nm}$ gold/palladium coating on the samples to make them conductive. 
A scanning electron microscope (SEM) Phenom XL (Thermo Fisher Scientific Inc.) was used to analyze the interaction between caffeine and theophylline and woods. The conditioned samples of the treated wood were dried in a vacuum desiccator, then mounted on aluminum stubs using double-sided conductive carbon tape and sputter coated with gold/palladium using a Quorum SC7620 sputter coater (Quorum Technologies Ltd.). An acceleration voltage of $15 \mathrm{kV}$, magnification of 90-7,500x, and a working distance of 2 to $20 \mathrm{~mm}$ were used for the microscopic analysis.

\section{Chemical analysis}

a) The three treated and the three control samples of beech and spruce wood were cut. Caffeine or theophylline concentrations were measured in two surface wooden layers (depth of layer from the surface 0.0 to $1.0 \mathrm{~mm}$; depth of 1.0 to $2.0 \mathrm{~mm}$ ). Layers were cut using a microtome and soaked in a known volume of distilled water for 168 hours. They were left in a thermostat in the dark and at $(20 \pm 2){ }^{\circ} \mathrm{C}$. Then $100 \pm 50 \mathrm{mg}$ of each wooden sample was used for leaching in distilled water. The concentrations of studied substances in wooden layers were analyzed by spectrophotometer Libra SX 22 at an optimal wavelength 287 nm (Kobetičová et al. 2021).

b) An aqueous stock solution of theophylline (1 g. $\left.\mathrm{L}^{-1}\right)$ was prepared for the experiment. Pure theophylline solution $\left(1 \mathrm{~g} . \mathrm{L}^{-1}\right)$ and pure cellulose or lignin mixtures $\left(1 \mathrm{~g} . \mathrm{L}^{-1}\right)$ were prepared as controls for analytical measurements. $1 \mathrm{~g}$ of cellulose or lignin powder was added into theophylline solution. The suspension of cellulose-theophylline was filtrated before the measurement. Triplicates were prepared for each mixture and for all of the control samples. The bottles were stored in a thermostat at a temperature of $(20 \pm 2){ }^{\circ} \mathrm{C}$ in the dark. The samples were analyzed after 168 hours of exposure. Determination of all solutions with or without theophylline $(5 \mathrm{~mL})$ was performed by UV-VIS spectrometry (spectrophotometer Biochrom Libra S22) at the optimal wavelength of theophylline $(287 \mathrm{~nm})$. The same experiment with caffeine was performed in a study of Kobetičová et al. (2021), and for this reason the test with caffeine was not repeated again. The caffeine concentration was 1 g.L.L (Kobetičová et al. 2021)

\section{Test species}

Serpula lacrymans (Schumacher ex Fries) Karsten (strain BAM Ebw. 315) and Coniophora puteana (Schumacher ex Fries) Karsten (strain BAM Ebw. 15) were used as model species. They were purchased from Timber Institute, Ltd., Prague, Czech Republic.

\section{Biological tests}

The treated or control specimens were stored in laboratory incubators at the test temperature $\left(-20,0,5,20\right.$, and $\left.40{ }^{\circ} \mathrm{C}\right)$ in glass Petri dishes for three months. The biological tests were then performed with sterile $3 \%$ maltose agar for the specimens inoculated by mold aerial spore-mixture and fungal mycelia. The mold spores were obtained from unspecific aerial molds covering Petri dishes with 3\% sterile maltose agar.

The biological test took place in defined laboratory conditions $\left(24 \pm 2{ }^{\circ} \mathrm{C}\right.$, in the dark) for three months. After incubation, the growth of mycelium on the top side of the samples was visually observed at $10 \times$ magnification and rated individually using the degree scale according to ISO EN 846 (1997), where 0 indicated no growth, 5 indicated heavy organismal growth. Surface fungal and mold mycelium was removed from each sample 
after microscopic visualization. The resistance was determined according to the average mass loss of the samples after the test by drying the samples at $5{ }^{\circ} \mathrm{C}$.

\section{Equations}

The equation of the calibration curve for calculation of caffeine and theophylline concentrations is expressed in the Eq. 1,

$$
y=0.0419 x-0.023
$$

where $y$ is a value of absorbance measured at wavelength $287 \mathrm{~nm}$ and $x$ is a calculated substance concentration.

The mass change $(\mathrm{MCH})$ of the samples dried at $(105 \pm 1){ }^{\circ} \mathrm{C}$ for five hours was calculated according to the Eq. 2,

$$
M C H=\left(m_{1}-m_{2}\right) 100 / m_{1}
$$

where $\mathrm{MCH}$ is the mass change of the samples $(\%), m_{1}$ is the initial dry mass before the substance application, and $m_{2}$ is the constant mass (dried) after the biological attack.

The inhibition data of mass changes and rating scale were determined by multivariate ANOVA, Dunnett Multiple Comparison Test, the growth data by multivariate ANOVA, and Tukey-Kramer Multiple Comparisons Test considering $\mathrm{P}<0.05$ as significant (GrapPad InStat, version 3.06; GraphPad Software Inc., San Diego, California, USA, 2003).

\section{RESULTS AND DISCUSSION}

Caffeine and theophylline concentrations were measured in two surface wooden layers (depth of layer from the surface 0 to $1 \mathrm{~mm}$ and the depth of 1 to $2 \mathrm{~mm}$ ) in the control and the treated wooden samples. The control samples did not contain any caffeine or theophylline levels. Binding of substances to wood samples was demonstrated in the treated samples. It is evident that caffeine was found in both layers and its concentrations were variable. Theophylline was not found in the lower layer of beech (Table 2). The changes in absorbance between two wooden layers were determined by Tukey-Kramer Multiple Comparisons Test at the significance level $\mathrm{P}<0.05$. The significantly different pairs were found only between the layers without substance and the adequate layers with substance concentrations. The data did not indicate the significant difference among the tested temperatures, but statistically significant changes were confirmed for the wooden layers of beech $(\mathrm{P}<0.001)$ and we can supposed that 1 . Lower levels of theophylline could bond to wood more than caffeine or 2. Caffeine is leached from wood more easily than theophylline.

The substances are able to create crystals, as is evident from Fig. 2. Theophylline crystals were larger than caffeine crystals, which may affect their different intensity of interactions with the wood surfaces and subsequent biodegradation. Bigger theophylline crystals are probably not able penetrate deeper layers of wood, as chemical analysis partly confirmed (Table 2) or maybe they are not retrospectively able to dissolve into distilled water from beech after their sorption to wood.

The occurrence of caffeine and theophylline within woods was also confirmed by SEM (Figs. 3 and 4). 
Table 2. Mean Absorbance Values $(A)$ at the Wavelength $287 \mathrm{~nm}$ and the Concentrations of Caffeine and Theophylline

\begin{tabular}{|c|c|c|c|c|c|}
\hline \multirow[t]{2}{*}{ Temperature } & \multirow[b]{2}{*}{$\begin{array}{l}\text { Depth of layer } \\
(\mathrm{mm})\end{array}$} & \multicolumn{2}{|c|}{ Beech } & \multicolumn{2}{|c|}{ Spruce } \\
\hline & & A & $\begin{array}{l}\text { Concentration } \\
\left(\mathrm{mg} \cdot \mathrm{g}^{-1} \text { wood) }\right.\end{array}$ & A & $\begin{array}{l}\text { Concentration } \\
\left(\mathrm{mg} . \mathrm{g}^{-1} \text { wood) }\right.\end{array}$ \\
\hline & & & Caffeine & & \\
\hline \multirow[t]{2}{*}{-20} & $0.0-1.0$ & 0.036 & 8.59 & 0.039 & 8.70 \\
\hline & $1.0-2.0$ & 0.036 & 8.60 & 0.076 & 18.1 \\
\hline \multirow[t]{2}{*}{0} & $0.0-1.0$ & 0.088 & 21.0 & 0.035 & 8.50 \\
\hline & $1.0-2.0$ & 0.033 & 8.45 & 0.080 & 20.2 \\
\hline \multirow[t]{2}{*}{5} & $0.0-1.0$ & 0.065 & 15.5 & 0.054 & 12.8 \\
\hline & $1.0-2.0$ & 0.025 & 5.97 & 0.058 & 13.0 \\
\hline \multirow[t]{2}{*}{20} & $0.0-1.0$ & 0.041 & 9.79 & 0.170 & 114 \\
\hline & $1.0-2.0$ & 0.044 & 9.82 & 0.048 & 10.0 \\
\hline \multirow[t]{3}{*}{40} & $0.0-1.0$ & 0.246 & 165 & 0.131 & 87.9 \\
\hline & $1.0-2.0$ & 0.020 & 13.4 & 0.001 & 0.00 \\
\hline & \multicolumn{5}{|c|}{ Theophylline } \\
\hline \multirow[t]{2}{*}{-20} & $0.0-1.0$ & 0.075 & 50.4 & 0.055 & 11.1 \\
\hline & $1.0-2.0$ & 0.000 & 0 & 0.000 & 8.25 \\
\hline \multirow[t]{2}{*}{0} & $0.0-1.0$ & 0.002 & 0.02 & 0.034 & 8.59 \\
\hline & $1.0-2.0$ & 0.013 & 0.04 & 0.000 & 0 \\
\hline \multirow[t]{2}{*}{5} & $0.0-1.0$ & 0.017 & 0.03 & 0.000 & 0 \\
\hline & $1.0-2.0$ & 0.000 & 0 & 0.025 & 1.67 \\
\hline \multirow[t]{2}{*}{20} & $0.0-1.0$ & 0.083 & 55,1 & 0.087 & 58.4 \\
\hline & $1.0-2.0$ & 0.000 & 0 & 0.161 & 56 \\
\hline \multirow[t]{2}{*}{40} & $0.0-1.0$ & 0.020 & 0.05 & 0.054 & 36.3 \\
\hline & $1.0-2.0$ & 0.000 & & 0.081 & 19.5 \\
\hline
\end{tabular}
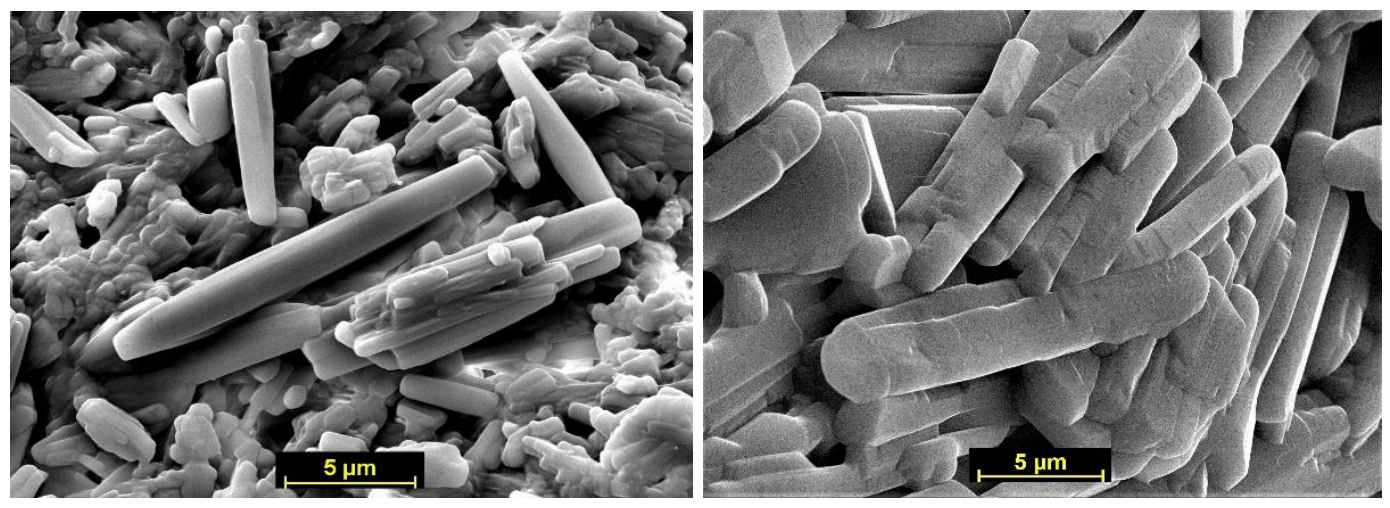

Fig. 2. Caffeine (left) and theophylline (right) crystal under FEG-SEM - Merlin-Zeiss electron microscope (10,000x magnification)

The other chemical analysis with main components of wood - cellulose or lignin, showed that theophylline interacts with lignin but not very well with cellulose (Table 3). The same conclusions were made for caffeine (Kobetičová et al. 2021). In percentage terms, smaller levels of caffeine $(28.3 \%)$ reacted with lignin than with theophylline $(64.7 \%)$. Cellulose is an inert material and produces a very limited reaction with caffeine as well as theophylline $(0.30 \%$ versus $7.41 \%)$. The percentage values for caffeine are based on the results from a study of Kobetičová et al. (2021). The inert properties of cellulose and bonds of caffeine to lignin were also confirmed by Kwasniewska et al. (2021). 

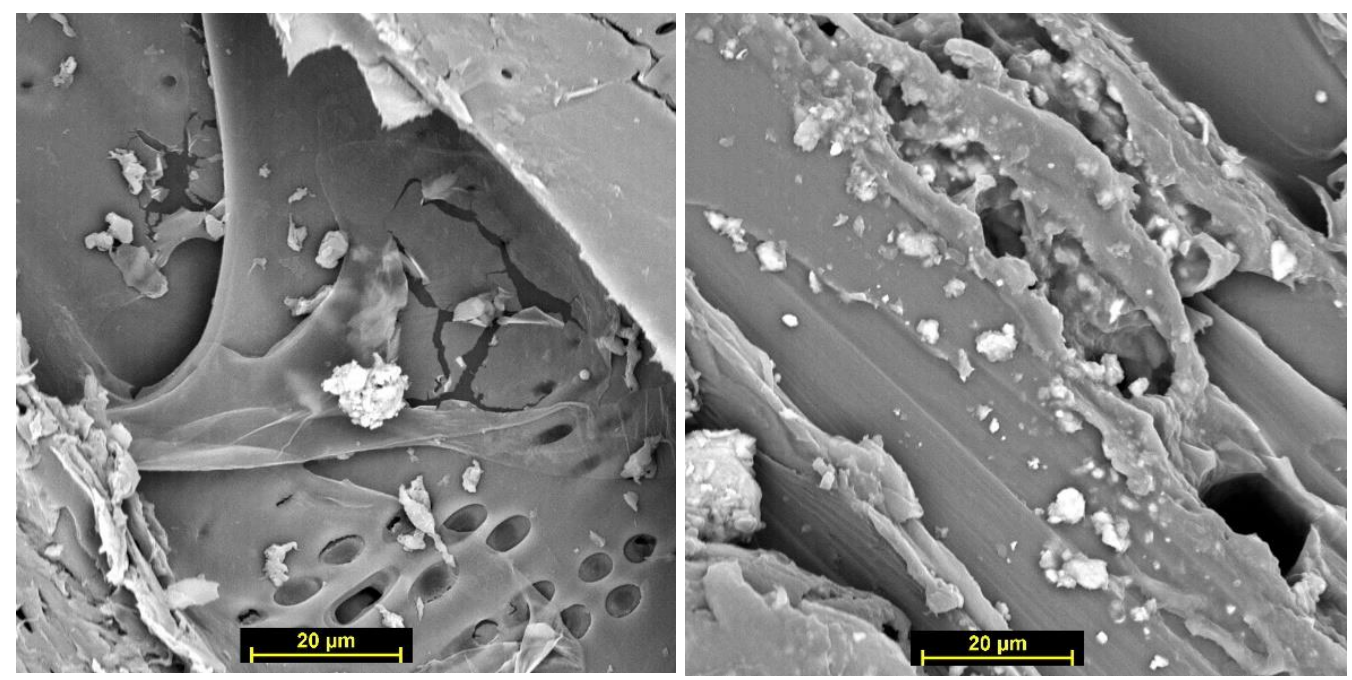

Fig. 3. The images of a vessel of wood treated with caffeine solution: beech (left) and spruce (right) showing caffeine at 3,000x magnification (SEM - Phenom XL)
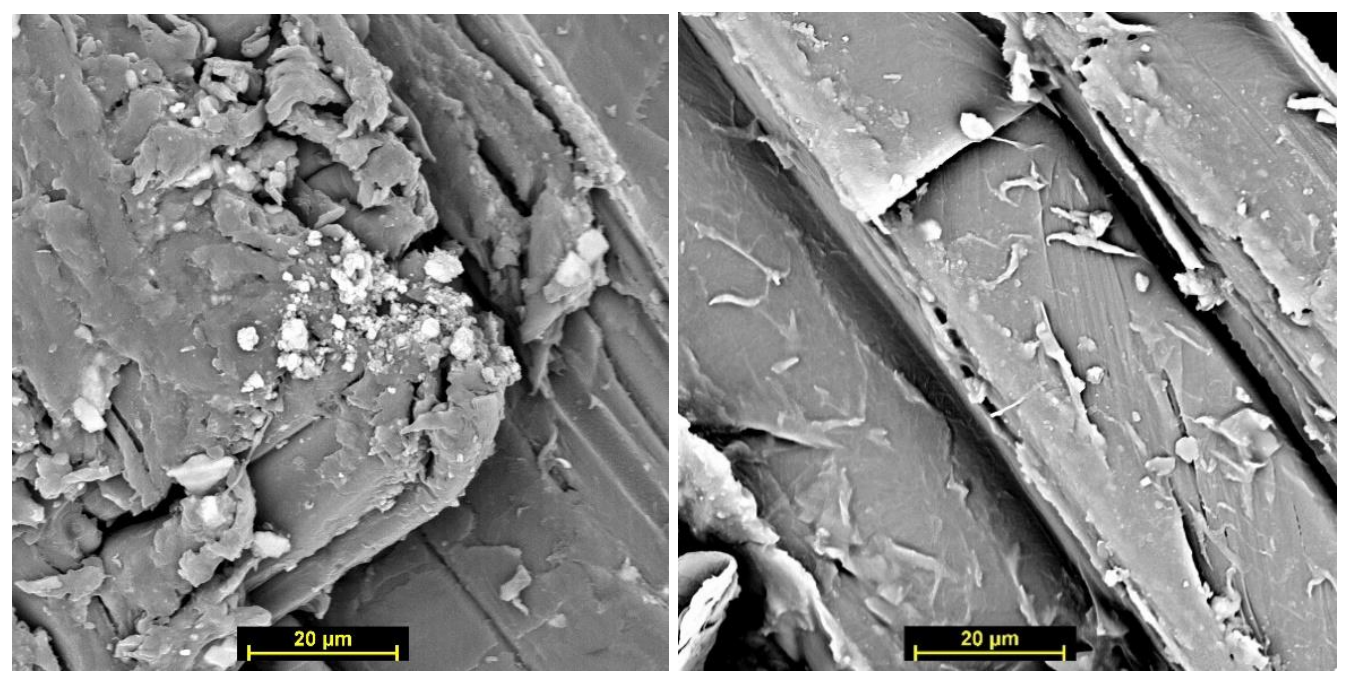

Fig. 4. Images of a vessel of wood treated with theophylline solution: beech (left) and spruce (right) showing theophylline at 3,000x magnification (SEM - Phenom XL)

Table 3. Mean Absorbance (A) of Theophylline Values: Theophylline (TP), Cellulose $(C)$, Lignin $(L)$, Theophylline-cellulose $(T P+C)$, Theophylline-lignin (TP $+\mathrm{L})$ Samples Measured at the Wavelength $287 \mathrm{~nm}$

\begin{tabular}{|l|l|l|l|l|}
\hline Line & Substance & Mean A \pm SD & $\begin{array}{c}\text { A of the TP: } \\
2 a-2,3 a-3\end{array}$ & $\begin{array}{c}\text { TP Interactions with Wood } \\
(\%) \text { in Comparison to the } \\
\text { TP Value (line 1=100\%) }\end{array}$ \\
\hline 1 & TP & $0.706(0.004)$ & & \\
\hline 2 & C & $0.079(0.007)$ & & \\
\hline 3 & L & $0.685(0.008)$ & & 07.41 \\
\hline 2a & TP + C & $0.754(0.004)$ & 0.675 & 64.73 \\
\hline $3 a$ & TP + L & $1.003(0.005)$ & 0.249 & \\
\hline
\end{tabular}

Three months of exposure to the mix of molds and fungi resulted in a considerable mass loss (ML) of control (untreated) spruce and beech specimens (Table 4). Spruce treated by caffeine was the most resistant (the lowest ML values) followed by beech treated by caffeine. On the other hand, both the woods treated by theophylline were less resistant to 
biological attack than control woods without treatment. The results of the mass loss experiments agreed well with the resistance rating tests compared on the basis of organism (Fig. 5). When comparing all data with each other (Table 3), significant differences (Tukey-Kramer Multiple Comparisons Test, $* * *, \mathrm{P}<0.05$ ) were found. These findings are very interesting because one could suppose adverse effect for theophylline, when its high amount was interacted with lignin in wood. However, the lignin experiments lasted only a short time (1 week) in the present study, but fungi of brown-rot degrade cellulose and hemicellulose and not lignin. Some other studied confirmed that theophylline can be used as a source of nutrient by some commercially cultured fungal species (Carrasco-Cabrera et al. 2019). In addition, its degradation over the course of time was observed - $66 \%$ during 28 days in aquatic solution (Kobetičová et al. 2020a). The higher toxic effect of caffeine to fungi may be perhaps explained by the weaker binding of caffeine to wood and its easier movement due to water.

Some results from the previous studies with pure aquatic caffeine solution indicate that spruce mass loss was less or similar to the present results, i.e. $2 \%$ in the case of Scots pine and fungal species Rhodonia placenta after 16 weeks (Šimůnková et al. 2021). Scots pine wood treated by caffeine was resistant approx. 0.7 to $2.5 \%$ against four wooddecaying fungi (Coniophora puteana, Poria placenta, Gloeophyllum trabeum, and Trametes versicolor) and against common mold fungi (Kwasniewska et al. 2018) after 16 weeks of exposure. This can be caused by a different resistance of pine wood. Pine is used as a reference wood in the resistance studies because this material is very sensitive to any biological attack.

Another reason for the greater resistance of caffeine-treated spruce can be the more complex biological community (mix of fungi and molds) used in our research simultaneously. Generally, molds can compete with fungi for space, nutrients, and moisture. The moisture is important for all wood-destroying fungi but molds have a faster growth rate than basidiomycetal fungi. Therefore, relatively fast-growing fungal species, $S$. lacrymans and Coniophora puteana, were used in this work for a better competitiveness with molds. The optimal growth temperature for fungi is species-specific from 20 to $35^{\circ} \mathrm{C}$. $S$. lacrymans and $C$. puteana optimally grow in the temperature range from 20 to $25^{\circ} \mathrm{C}$, whereas molds are optimal from 25 to $35^{\circ} \mathrm{C}$. The temperature conditions of $(24 \pm 2){ }^{\circ} \mathrm{C}$ used in the biological experiments in this study was thus suitable for both analyzed fungi and molds. Degradation of wood by fungi is expressed by mass loss and the damage of wood by mold by rating scale (Kwasniewska et al. 2018). In the last studies, some lower mass losses were found after exposition to molds + fungi in the case of unspecific aerial molds, spruce, beech (Kobetičová et al. 2020b) or only beech (Kobetičová et al. 2020b; Šimůnková et al. accepted).

The results from the test with theophylline obtained in this paper could not be compared directly with the studies published by other investigators as no data for spruce and beech treated by theophylline are in the common literature sources.

Two kinds of woods (beech, spruce) were used in the present experiment. They have relatively variable composition of lignin (spruce about $20 \%$, beech about $30 \%$ ) and cellulose (40 to 50\%) according to literature (Pettersen 1984). Their compositions such should have a large significance for caffeine and theophylline bindings to tested wooden materials, mainly in the uppermost layer of wood and their re-release and its interaction with the environment (water, UV). On the other hand, wood contains also hemicellulose, fats, and the other additional substances. Their effects on bindings of methylxathines to wood have never been studied.

Kobetičová et al. (2021). "Caffeine \& wood protection," BioResources 16(3), 6231-6243. 6238 
Table 4. Mean Mass Change (\%) with Standard Deviation (SD) of Spruce (S) and Beech (B) Woods Treated by Caffeine (CAF) or Theophylline (TP) and Controls (DW) for Various Treatment Temperatures $\left(-20,0,5,20,40^{\circ} \mathrm{C}\right)$ and Mass Inhibition (I) of Treated Samples in Comparison with Control Samples (\%)

\begin{tabular}{|c|c|c|c|c|c|c|}
\hline Spruce (S) & \multicolumn{2}{|c|}{$\begin{array}{c}\text { CAF } \\
\left(20 \mathrm{~g}^{-\mathrm{L}^{-1}}\right)\end{array}$} & \multicolumn{2}{|c|}{$\begin{array}{c}\text { TP } \\
\left(5.5{\mathrm{~g} . \mathrm{L}^{-1}}^{-1}\right)\end{array}$} & \multicolumn{2}{|c|}{ DW } \\
\hline $\begin{array}{c}\text { Temperature } \\
\left({ }^{\circ} \mathrm{C}\right)\end{array}$ & $\begin{array}{l}\text { Mean } \\
(\%)\end{array}$ & $\mathrm{SD}( \pm)$ & Mean (\%) & $\begin{array}{l}\text { SD } \\
( \pm)\end{array}$ & Mean (\%) & $\mathrm{SD}( \pm)$ \\
\hline-20 & 2.34 & 0.36 & 6.92 & 3.56 & 4.01 & 0.62 \\
\hline 0 & 2.47 & 1.49 & 8.59 & 3.45 & 4.62 & 0.42 \\
\hline 5 & 4.84 & 2.74 & 8.69 & 0.68 & 5.42 & 0.41 \\
\hline 20 & 2.57 & 0.50 & 8.06 & 3.15 & 3.68 & 2.47 \\
\hline 40 & 1.92 & 0.22 & 7.39 & 3.01 & 5.73 & 2.99 \\
\hline Beech (B) & \multicolumn{2}{|c|}{$\begin{array}{c}\text { CAF } \\
\left(20 \mathrm{~g} \cdot \mathrm{L}^{-1}\right)\end{array}$} & \multicolumn{2}{|c|}{$\begin{array}{c}\text { TP } \\
\left(5.5 \mathrm{~g} . \mathrm{L}^{-1}\right)\end{array}$} & \multicolumn{2}{|c|}{ DW } \\
\hline $\begin{array}{c}\text { Temperature } \\
\left({ }^{\circ} \mathrm{C}\right)\end{array}$ & $\begin{array}{l}\text { Mean } \\
(\%)\end{array}$ & $\mathrm{SD}( \pm)$ & Mean (\%) & $\begin{array}{l}\text { SD } \\
( \pm)\end{array}$ & Mean (\%) & SD ( $( \pm)$ \\
\hline-20 & 3.62 & 0.27 & 5.44 & 6.59 & 4.44 & 0.16 \\
\hline 0 & 4.76 & 2.77 & 6.32 & 0.27 & 4.74 & 0.18 \\
\hline 5 & 2.97 & 0.71 & 6.14 & 0.46 & 4.81 & 0.16 \\
\hline 20 & 3.67 & 0.06 & 5.72 & 6.05 & 4.79 & 0.23 \\
\hline 40 & 4.15 & 1.09 & 6.22 & 0.25 & 3.13 & 2.58 \\
\hline
\end{tabular}

The mean mass changes were determined by Tukey-Kramer Multiple Comparisons Test at the significance level $P<0.05$. The differently significant pairs are the following (expressed as $P$ values): CAF vs TP: ${ }^{* *} \mathrm{P}<0.001$; CAF vs DW: ${ }^{*} \mathrm{P}<0.05$; TP vs DW: ${ }^{* *} \mathrm{P}<0.001$.

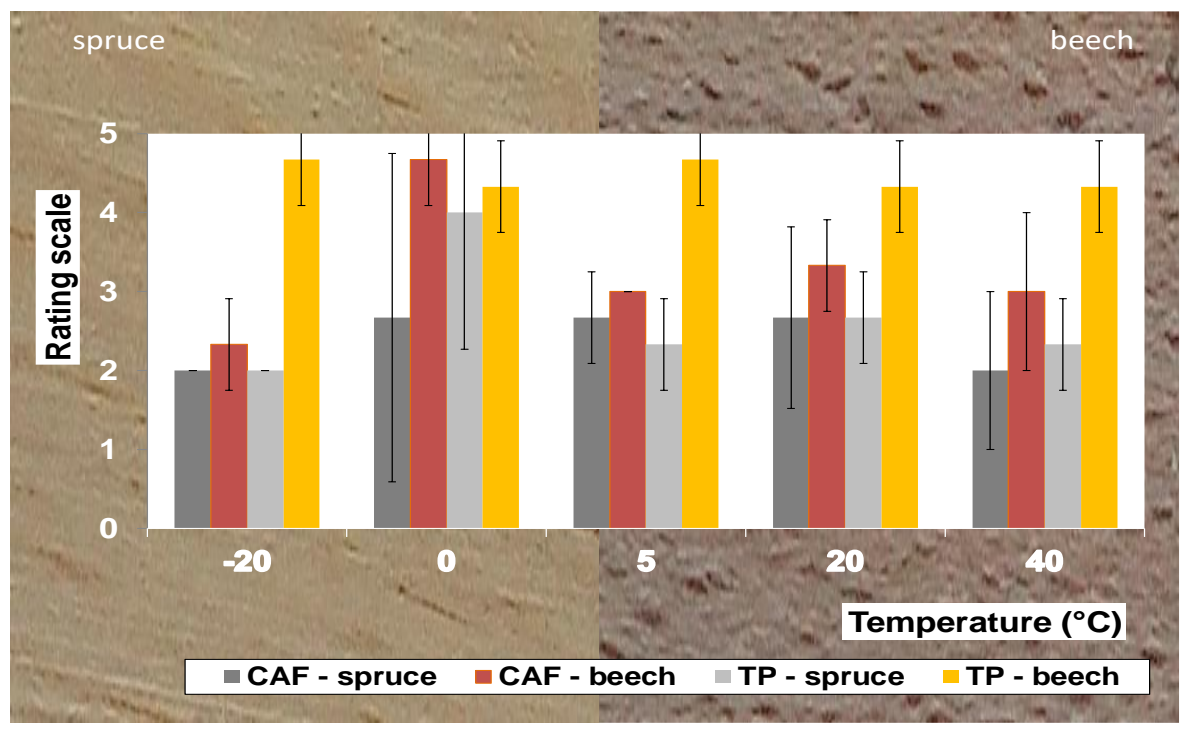

Fig. 5. Scheme of biodegradation (rating scale). Organismal resistance rating scale: 0 - no visible growth under the microscope, 1 - growth invisible to the naked eye, but clearly visible under the microscope, 2 - coverage of up to $25 \%$ of the tested sample, 3 - coverage of up to $50 \%$ of the tested sample, 4 - coverage of more than $50 \%$ of the tested sample, 5 -intensive growth covering the entire surface of the tested sample. 
Table 5. Statistical Evaluation of: 1) Mass Changes (g) Among the Spruce (S) and Beech (B) Woods Treated by Caffeine (CAF) or Theophylline (TP) and 2) Rating Scales of Woods (S, B) and Substances (CAF, TP); 3) Chemical Analysis - Absorbance (A) Values between Control and Theophylline or Caffeine Treatment at the Individual Temperatures

\begin{tabular}{|c|c|c|c|}
\hline Comparison 1 & Difference & $\mathbf{q}$ & $P$ value \\
\hline CAF - S vs CAF - B & -1.006 & 2.848 & ns $P>0.05$ \\
\hline CAF - S vs TP - S & -5.102 & 14.444 & *** $\mathrm{P}<0.001$ \\
\hline CAF - S vs TP - B & -3.140 & 8.890 & *** $\mathrm{P}<0.001$ \\
\hline CAF - B vs TP - S & -4.096 & 11.596 & *** $\mathrm{P}<0.001$ \\
\hline CAF - B vs TP - B & -2.134 & 6.042 & ${ }^{* *} \mathrm{P}<0.01$ \\
\hline TP - S vs TP - B & 1.962 & 5.555 & ${ }^{* *} P<0.01$ \\
\hline Comparison 2 & Difference & $q$ & P value \\
\hline CAF - S vs CAF - B & -1.266 & 3.266 & ns $P>0.05$ \\
\hline CAF - S vs TP - S & -0.666 & 1.718 & ns $P>0.05$ \\
\hline $\mathrm{CAF}-\mathrm{S}$ vs TP - B & -2.466 & 6.362 & ** $\mathrm{P}<0.01$ \\
\hline CAF - B vs TP - S & 0.600 & 2.048 & ns $P>0.05$ \\
\hline CAF - B vs TP - B & -1.200 & 4.095 & ns $P>0.05$ \\
\hline TP - S vs TP - B & -1.800 & 6.143 & ** $\quad \mathrm{P}<0.01$ \\
\hline
\end{tabular}

Notes: One-way ANOVA and Tukey-Kramer Multiple Comparisons Test at the Significance Level $\mathrm{P}<0.05$

The effects of natural, artificial, or simulated weather conditions on the properties and resistance of various woods were analyzed, as described by Kropat et al. (2020) in a recent review. Very high significance has been reported for solar radiation, mainly UV light (Zahri et al. 2007; Timar et al. 2016), rainfall, and pests. However, an interpretation of results from in situ experiments is relatively complicated because there are many influencing factors. For this reason, some accelerated weathering tests are often performed for easier prediction, understanding, and reproducibility (Kropat et al. 2020). However, no analyses of the effect of temperature separated from the other naturally or artificially occurring factors, except for that performed in this paper, have been reported yet in common literature sources. In the present study, temperatures within the range of -20 to 40 ${ }^{\circ} \mathrm{C}$, simulating weather conditions in the European region and temperatures specific for various wood applications, did not affect the sorption of protective substances and their biological resistance (Table 4, Fig. 5). These findings indicated that caffeine as protective substance should be used in environments with constant temperature (flats, trusses, warehouses, cellars, etc.) rather than in outdoor conditions because an effect of UV radiation and caffeine leaching negatively affected using of caffeine for protection purposes (Pánek et al. 2020).

In an explanation of differences in the effectiveness of both methylxanthines applied for wood protection in this paper, the substances concentrations and the long-term stability of the substances should have been taken into an account. Kobetičová et al. (2020) showed in agar tests that the theophylline degradation was up 34\% after 28 days of exposure and increased with increasing temperature in a range of 20 to $35^{\circ} \mathrm{C}$. Caffeine was found to have a much longer stability (86\%). The chemical properties, such as dipole moment (higher caffeine solubility in aquatic solutions), lipophilicity (caffeine higher affinity to wood structures and its higher stability), and electrophilicity (ability to uptake electron and create bonds with the organic nucleophiles of pests or wood structure) have effect on substances bindings to wood and consequently affect the effectiveness against 
pests to caffeine contrary to theophylline as it was indicated in a study of Kobetičová et al. (2020a) for the same fungal species in vitro agar tests. Binding potential followed by different decaying by pests can be also explained by variable properties between spruce and beech wood. Beech is generally more sensitive to biological attacks than spruce thanks its higher permeability and aquatic retention (EN 350, 2016).

Properties of beech and spruce wood after caffeine treatment were studied in some recent studies. Specifically, Borůva et al. (accepted) observed the effect of the treatment on selected physical and mechanical properties, specifically wood density, swelling, and compressive strength. No significant effect of caffeine modification of beech wood was confirmed without and after weathering in the case of the tested physical and mechanical properties. In the other work (Šimůnková et al., accepted) investigated the effect of dipping of beech wood by caffeine aquatic solution and its effect on the change of gloss, color, contact wetting angle, and surface free energy. Furthermore, the impact of artificial accelerated weathering in Xenotest was assessed. Modifications of wood with caffeine and wood dipping were found to have no significant impact on the properties of beech. Spruce treatment by caffeine was also studied (Šimůnková et al. 2021).

Theophylline effects on beech and spruce properties were not studied in any study but it can be supposed that methylxathines are not suitable for the surface treatment of beech against pests in the case of pure aqueous solutions without the addition of other substances or protective coatings. Theophylline treatment also caused lower bio-resistance than at the control samples without any treatment and this fact, together with its degradations, unfortunately excludes it from possible use against wood-destroying pests.

\section{CONCLUSIONS}

1. The temperatures in range of -20 to $40{ }^{\circ} \mathrm{C}$ did not have any significant effect on wood bio-resistance to pests.

2. Caffeine was found as more effective than theophylline for protection of spruce and beech wood against fungi and molds.

3. The protective effect was higher for spruce than for beech.

4. Caffeine can be recommended as a non-toxic bioactive substance suitable for spruce and spruce - based materials protection in a stable indoor temperature environment.

5. Binding of theophylline to lignin in contrary to cellulose was confirmed for the first time.

\section{ACKNOWLEDGMENTS}

This research has been supported by the Czech Science Foundation under Project No. 19-02067S and by the Grant Agency of the Czech Technical University in Prague under project No. SGS19/143/OHK1/3T/11. The authors also appreciate the help of Pavel Kobetič with the preparation of wood samples. 


\section{REFERENCES CITED}

Borůvka, V., Zeidler, A., Schönfelder, O., and Šimůnková, K. (accepted). “Selected physical and mechanical properties of beech wood treated by caffeine," in: $9^{\text {th }}$ Hardwood Proceedings. PT. I., An Underutilized Resource: Hardwood Oriented Research.

Broda, M. (2020). "Natural compounds for wood protection against fungi - A Review," Molecules 25, 3538. DOI: 10.3390/molecules25153538

Broda, M., Mazela, B., and Frankowski, M. (2018). "Durability of wood treated with aatmos and caffeine-towards the long-term carbon storage," Maderas-Cienc.Tecnol. 20, 455-468. DOI: 10.4067/S0718-221X2018005031501

Carrasco-Cabrera, C. P., Bell, T. L., and Kertesz, M. A. (2019). "Caffeine metabolism during cultivation of oyster mushroom (Pleurotus ostreatus) with spent coffee grounds," Appl. Microb. Biotechnol. 103(14), 5831. DOI: 10.1007/s00253-01909883-z

ISO EN 846 (1997). "Plastics. Evaluation of the action of microorganisms"

ISO EN 350 (2016). "Durability of wood and wood-based products-Testing and classification of the durability to biological agents of wood and wood-based materials," European Committee for Standardization: Brussels, Belgium, 2016

Kobetičová, K., Kočí, V., Petř́ḱková, M., Šimůnková, K., and Černý, R. (2019). “Growth effectivity of molds in contact with methylxanthines," MATEC Web of Conferences 282, 02058. DOI: 10.1051/matecconf/201928202058.

Kobetičová, K., Nábělková, J., Ďurišová, K., Šimůnková, K., and Černý, R. (2020a). "Antifungal activity of methylxanthines in relation to their properties," BioResources 15(4), 8110-8120. DOI: 15.4.8110-8120

Kobetičová, K., Böhm, M., and Černý, R. (2020b). "Mutual interactions of fungi and molds on woods treated with a caffeine solution: A preliminary study," AIP Conference, Proceedings 2275, 020010. DOI: 10.1063/5.0025855

Kobetičová, K., Durišová, K., and Nábělková, J. (2021). "Caffeine interactions with wood polymers," Forests 12(5), 533. DOI: 10.3390/f12050533

Kropat, M., Hubbe, M. A., and Laleicke, F. (2020). "Natural, accelerated and simulated weathering of wood: A Review," BioResources 15(4), 9998-10062.

Kwasniewska-Sip, P., Cofta, G., and Nowak, P. B. (2018). "Resistance of fungal growth on Scots pine treated with caffeine," Int. Biodeterior. Biodegrad. 132, 178-184. DOI: 10.1016/j.ibiod.2018.03.007

Kwasniewska-Sip, P., Bartkowiak, M., Cofta, G., and Nowak, P. B. (2019). "Resistance of Scots pine (Pinus sylvestris L.) after treatment with caffeine and thermal modification against Aspergillus niger," BioResources 14, 1890-1898. DOI: 10.15376/biores.14.1.1890-1898

Kwasniewska-Sip, P., Wozniak, M., Jankowski, W., and Ratajczak, I. (2021). "Chemical changes of wood treated with caffeine," Materials 14(3), 497. DOI: 10.3390/ma14030497

Pánek, M., Šimůnková, K., Novák, D., Dvořák, O., Schönfelder, O., Šedivka, P., and Kobetičová, K. (2020). "Caffeine and $\mathrm{TiO}_{2}$ nanoparticles treatment of spruce and beech wood for increasing transparent coating resistance against UV- Radiation and mould attacks," Coatings 10, 1141. DOI: 10.3390/coatings10121141 
Pettersen, R. C. (1984). "The chemical composition of wood," in: The Chemistry of Solid Wood, R. M. Rowell (ed.), Advances in Chemistry Series 207. Washington, D.C., American Chemical Society, Chapter 2

Ratajczak, I., Wozniak, M., Kwasniewska-Sip, P., Szentner, K., Cofta, G., and Mazela, B. (2018). "Chemical characterization of wood treated with a formulation based on propolis, caffeine and organosilanes," Eur. J. Wood Wood Prod. 76, 775-781. DOI: 10.1007/s00107-017-1257-9

Šimůnková, K., Reinprecht, L., Nábělková, J., Hýsek, Š., Kindl, J., Borůvka, V., Lišková, T., Šobotník, J., and Pánek, M. (2021). "Caffeine - Perspective natural biocide for wood protection against decaying fungi and termites," J. Clean. Prod. 304, article no. 127110. DOI: 10.1016/j.jclepro.2021.127110

Šimůnková, K., Zeidler, A., Schönfelder, O., and Pánek, M. (accepted). "Impact of modification by caffeine on some surface properties of beech wood," in: $9^{\text {th }}$ Hardwood Proceedings, Pt. I. An Underutilized Resource: Hardwood Oriented Research

Timar, M. C., Varodi, A. M., and Gurău, L. (2016). "Comparative study of photodegradation of six wood species after short-time UV exposure," Wood Sci. Technol. 50, 135-163.

Zahri, S., Belloncle C., Charrier, F., Pardon, P., Quideau S, S., and Charrier, B. (2007). "UV light impact on ellagitannins and wood surface colour of European oak (Quercus petraea and Quercus robur)," Appl. Surf. Sci. 253, 4985-4989.

Article submitted: February 1, 2021; Peer review completed: March 27, 2021; Revised version receives and accepted: July 17, 2021; Published: July 26, 2021.

DOI: 10.15376/biores.16.3.6231-6243 